\title{
Ixora coccinea extract as an efficient eco-friendly corrosion inhibitor in acidic media: Experimental and theoretical approach
}

\author{
Vidhya Thomas Ka , Joby Thomas Kakkassery ${ }^{a}$, Vinod P. Raphael ${ }^{b}$, K. Ragi and Reeja \\ Johnson ${ }^{\text {a }}$
}

${ }^{a}$ Centre for Electrochemical Studies, Department of Chemistry, St. Thomas' College (Autonomous), Thrissur, Kerala 680001, India ${ }^{b}$ Department of Chemistry, Government Engineering College, Thrissur, Kerala, India

\begin{tabular}{l} 
C H R O N I C L E \\
\hline Article history: \\
Received August 1, 2020 \\
Received in revised form \\
November 29, 2020 \\
Accepted December 14, 2020 \\
Available online \\
December 14, 2020 \\
\hline Keywords: \\
Mild steel \\
ICE \\
Ixorene \\
EIS \\
Adsorption
\end{tabular}

\section{Introduction}

In recent years, green chemistry has been gaining traction in the research world, owing to a demand for chemical technologies and commercial products that are less toxic and generate less waste. One of the promising domains, for the application of green chemistry principles, is the protection of metals from corrosion. Most of the industries work in an acidic environment which causes metal corrosion, leading to loss of metal. The best and favourable method to reduce metal degradation is the usage of corrosion inhibitors $^{1-3}$. Organic compounds with heteroatoms like $\mathrm{N}, \mathrm{O}, \mathrm{S}$, etc. in a conjugated system have been commonly used as inhibitors and they can interact with metal either by chemisorption or physisorption $^{4-5}$. The adsorptive layer formed on the metal surface protects from the acidic solution and thereby minimizing corrosion. Due to eco-friendliness, low cost, readily available and renewable source of material, natural products like plant extracts can be used as green corrosion inhibitors ${ }^{6-8}$.

\footnotetext{
* Corresponding author.

E-mail address: drjobythomask@gmail.com (J. Thomas Kakkassery)
}

(C) 2021 Growing Science Ltd. All rights reserved. doi: $10.5267 /$ j.ccl.2020.12.001 
Several plant-based extracts successfully inhibited the corrosion of metals in an acidic environment. For example, Musa paradisica indicates $90 \%$ inhibition efficiency at $300 \mathrm{mg} / \mathrm{L}^{9}$, Kola nitida demonstrates $78 \%$ hindrance effectiveness at $1200 \mathrm{mg} / \mathrm{L}^{10}$, Butea monosperma demonstrates $98 \%$ restraint effectiveness at $500 \mathrm{mg} / \mathrm{L}^{11}$. Logan seed and peel extract has been utilized for corrosion inhibitor in acidic media ${ }^{12}$. $\beta$-sitosterol isolated from rice hulls has been reported as a good corrosion inhibitor for mild steel in acidic environments ${ }^{13}$. Strychnos nuxvomica, Piper longum and Mucuna pruriens seed extracts have been found as eco-friendly corrosion inhibitors for copper in nitric acid ${ }^{14}$. Lemongrass extract was evaluated for its anti-corrosion action in produced oilfield water ${ }^{15}$.

In the present work, we have studied the corrosion inhibition efficiency of ethanolic extract of Ixora coccinea (Rubiaceae family) leaves for mild steel in $1 \mathrm{M} \mathrm{HCl}$ and $0.5 \mathrm{M} \mathrm{H}_{2} \mathrm{SO}_{4}$ media. The major component of Ixora coccinea leaves is ixorene which is a triterpenoid containing a hydroxyl group and unsaturated bonds, which causes anti-corrosion potential ${ }^{16}$. To evaluate the corrosion inhibition ability of the leaf extract in more detail, the major component ixorene was subjected to theoretical calculations.

\section{Results and Discussion}

\subsection{FT-IR Spectroscopy}

To identify the functional groups existing in ICE, FT-IR spectroscopy of dried powdered Ixora coccinea leaves has been examined and it is shown in Fig. 1. The peak at $3438 \mathrm{~cm}^{-1}$ indicates $\mathrm{O}-\mathrm{H}$ stretching bond. The peaks at $2928 \mathrm{~cm}^{-1}$ and $2850 \mathrm{~cm}^{-1}$ are pointed alkyl C-H stretching bonds. The peaks at $1384 \mathrm{~cm}^{-1}$ and $1628 \mathrm{~cm}^{-1}$ represent $\mathrm{C}=\mathrm{C}$ and aromatic $\mathrm{C}=\mathrm{C}$ stretching bonds respectively. The other significant peaks indicate the presence of minor components present in ICE.

\subsection{Weight Loss Measurements}

\subsubsection{Effect of concentration of inhibitor}

The weight loss measurements of mild steel in $1 \mathrm{M} \mathrm{HCl}$ and $0.5 \mathrm{M} \mathrm{H}_{2} \mathrm{SO}_{4}$ solutions at room temperature with and without various concentrations (1-5 v/v \%) of ICE for 24 hours are recorded in Table 1. It is evident from the data that as the concentration of inhibitor is increased; the percentage inhibition efficiency also increases in both the acidic media. The results show that ICE is an efficient inhibitor in $1 \mathrm{M} \mathrm{HCl}$ attaining maximum inhibition efficiency at $5 \%$ as $89.38 \%$. This is due to the number of adsorbed organic molecules of inhibitor ICE on mild steel is more in $\mathrm{HCl}$ than $\mathrm{H}_{2} \mathrm{SO}_{4}$ medium.

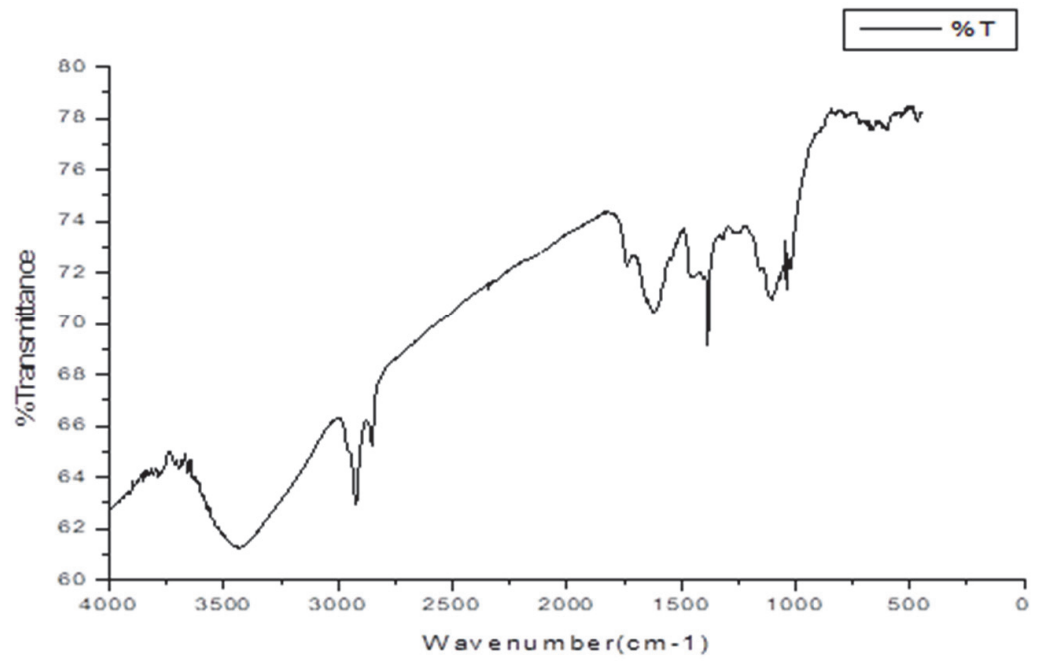

Fig. 1. FT-IR spectrum of dried powdered Ixora coccinea leaves 
Table 1.Weight loss measurements of mild steel with and without various concentrations of ICE in 1 $\mathrm{M} \mathrm{HCl}$ and $0.5 \mathrm{M} \mathrm{H}_{2} \mathrm{SO}_{4}$

\begin{tabular}{ccc|cc}
\hline $\begin{array}{c}\text { ICE conc. } \\
(\mathrm{v} / \mathrm{v} \%)\end{array}$ & \multicolumn{2}{c|}{$1 \mathrm{M} \mathrm{HCl}$} & \multicolumn{2}{c}{$0.5 \mathrm{M} \mathrm{H}_{2} \mathrm{SO}_{4}$} \\
\cline { 2 - 5 } & Corrosion rate (v) & $\begin{array}{c}\text { Inhibition efficiency }(\eta \\
\%)\end{array}$ & $\begin{array}{c}\text { Corrosion rate (v) } \\
\text { Inhibition efficiency }(\eta \\
\%)\end{array}$ \\
\hline Blank & 3.95 & - & 35.57 & - \\
1 & 0.60 & 84.77 & 12.23 & 65.61 \\
2 & 0.56 & 85.75 & 11.52 & 67.58 \\
3 & 0.52 & 86.73 & 9.05 & 74.53 \\
4 & 0.47 & 87.98 & 8.77 & 75.32 \\
5 & 0.41 & 89.38 & 7.83 & 77.96 \\
\hline
\end{tabular}

\subsubsection{Effect of time on medium: UV-Visible Spectroscopy}
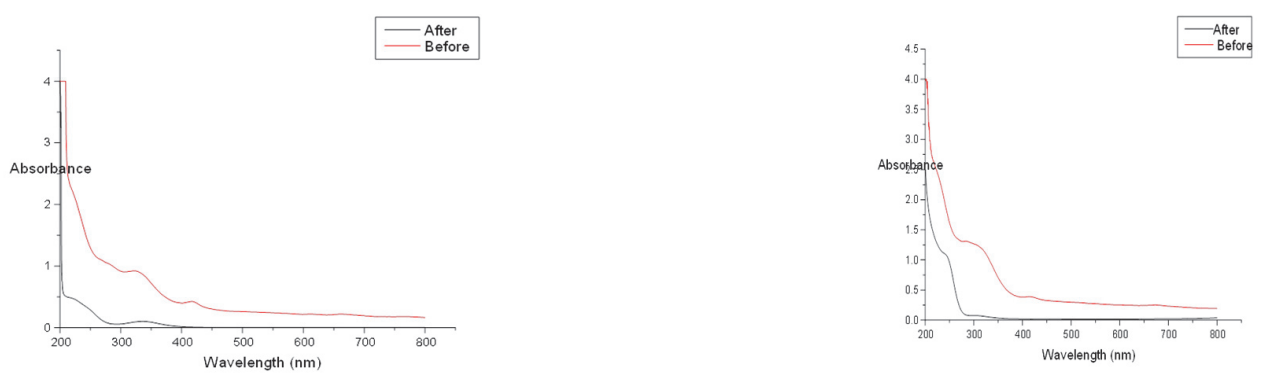

Fig. 2. UV-Visible spectroscopy of medium a) $1 \mathrm{M} \mathrm{HCl}$ and b) $0.5 \mathrm{M} \mathrm{H}_{2} \mathrm{SO}_{4}$ before and after 24 hrs of immersion period with $1 \%$ ICE solution

Any prominent shift in the position of the absorbance maximum of the medium measured before and after the immersion of mild steel with inhibitor points to an interaction between Iron and inhibitor molecules. ${ }^{17-19}$. From Fig. 2, it's clear that in both $\mathrm{HCl}$ and $\mathrm{H}_{2} \mathrm{SO}_{4}$ medium, there is a lowering of absorbance of absorption maxima after $24 \mathrm{hrs}$ of immersion of mild steel, even though both spectra have a similar shape. So, this lowering of absorbance after the immersion of mild steel can be attributed to the adsorption of some molecules of ICE from the solution on the mild steel surface.

\subsection{Electrochemical studies}

\subsubsection{Electrochemical Impedance Spectroscopy}

EIS studies are alternate current methods mainly used to analyse the corrosion behaviour at metal/solution interface ${ }^{20}$. The equivalent circuit employed in this study is Randle's circuit (Fig. 3). It includes solution resistance $R_{s}$, charge transfer resistance $R_{c t}$ and double layer capacitance $C_{d l}$. The deformities on the metal surface cause deviations from the ideal dielectric property of the metal. So, a constant phase element (CPE) is preferred to $\mathrm{C}_{\mathrm{dl}}{ }^{21}$.

$$
\mathrm{Z}_{\mathrm{CPE}}=\mathrm{Q}^{-1}(\mathrm{j} \omega)^{-\mathrm{n}}
$$

where $\mathrm{Q}$ is the measure of CPE, $\mathrm{n}$ is the power of the magnitude of $\mathrm{CPE}, \omega$ is the angular frequency and $\mathrm{j}$ is the imaginary unit. The Nyquist and Bode plots of mild steel without and with the inhibitor ICE using various concentrations $(1-5 \mathrm{v} / \mathrm{v} \%)$ in $1 \mathrm{M} \mathrm{HCl}$ and $0.5 \mathrm{M} \mathrm{H}_{2} \mathrm{SO}_{4}$ at room temperature are shown in Fig. 4 and Fig. 5. In Nyquist plots, it is seen that the low-frequency region is plotted to a straight line and the high-frequency region is plotted to a semi-circle. The slight fall in the semi-circular plot is ascribed to the heterogeneous and roughness of the mild steel. The straight-line portion represents the 
diffusion from solution ${ }^{22}$. As the concentration of ICE is raised, the size of the loop also increases. This is can be ascribed to the increase in the impedance of inhibited mild steel. The efficiency also increases in the process. The impedance data obtained from the above equivalent circuit for both media are given in Table 2.

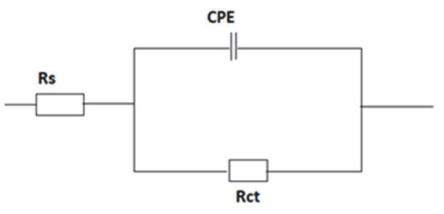

Fig. 3. Randles circuit used for electrochemical measurements

As the concentration of inhibitor increases, double-layer capacitance $\left(\mathrm{C}_{\mathrm{dl}}\right)$ decreases which indicates that the thickness of the electrical double layer increases with respect to the concentration. This is due to the adsorption of inhibitor molecules on the mild steel surface. The maximum inhibition efficiency of $91.55 \%$ is seen at a $5 \%$ concentration of ICE in $1 \mathrm{M} \mathrm{HCl}$.
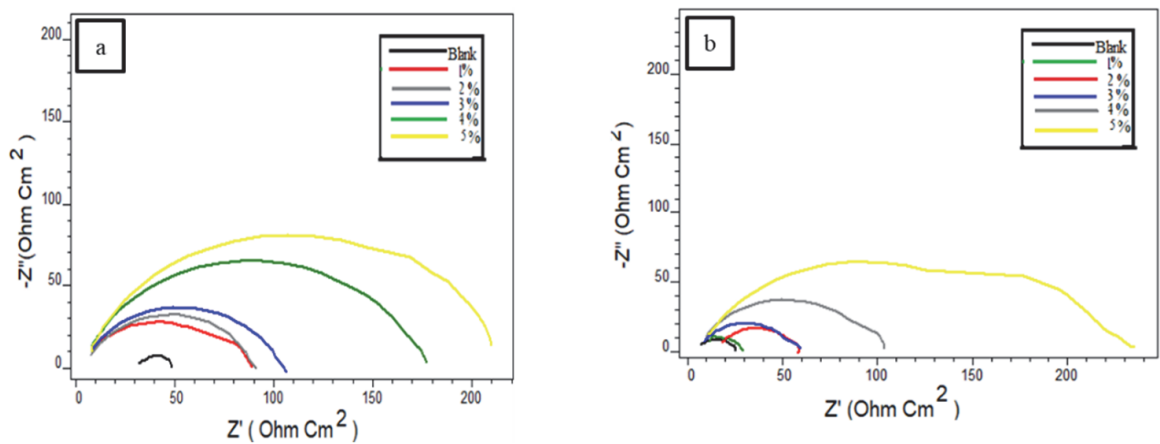

Fig. 4. Nyquist plots of mild steel with and without ICE in a) $1 \mathrm{M} \mathrm{HCl}$ and b) $0.5 \mathrm{M} \mathrm{H}_{2} \mathrm{SO}_{4}$
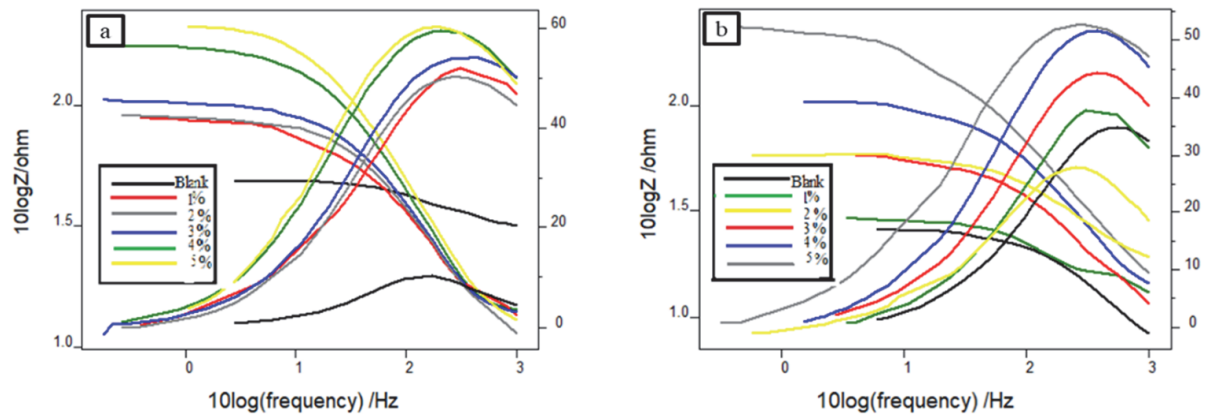

Fig. 5. Bode plots of mild steel with and without ICE in a) $1 \mathrm{M} \mathrm{HCl}$ and b) $0.5 \mathrm{M} \mathrm{H}_{2} \mathrm{SO}_{4}$

Table 2. Impedance parameters for mild steel in $1 \mathrm{M} \mathrm{HCl}$ and $0.5 \mathrm{M} \mathrm{H}_{2} \mathrm{SO}_{4}$ with and without various concentrations of ICE

\begin{tabular}{|c|c|c|c|c|c|c|}
\hline \multirow{2}{*}{ ICE conc. (v/v \%) } & \multicolumn{3}{|l|}{$1 \mathrm{M} \mathrm{HCl}$} & \multicolumn{3}{|c|}{$0.5 \mathrm{M} \mathrm{H}_{2} \mathrm{SO}_{4}$} \\
\hline & $\mathrm{R}_{\mathrm{ct}}\left(\Omega \mathrm{cm}^{2}\right)$ & $\mathrm{C}_{\mathrm{dl}}\left(\mu \mathrm{Fcm}^{-2}\right)$ & $\eta_{\text {EIS }} \%$ & $\mathrm{R}_{\mathrm{ct}}\left(\Omega \mathrm{cm}^{2}\right)$ & $\mathrm{C}_{\mathrm{dl}}\left(\mu \mathrm{Fcm}^{-2}\right)$ & $\eta_{\text {EIS }} \%$ \\
\hline Blank & 15.7 & 78.8 & - & 18.1 & 47.4 & - \\
\hline 1 & 69.7 & 57.4 & 77.47 & 20.3 & 50.5 & 10.83 \\
\hline 2 & 73.9 & 49.6 & 78.74 & 37.4 & 39.0 & 51.56 \\
\hline 3 & 86.4 & 49.7 & 81.82 & 44.1 & 36.9 & 58.93 \\
\hline 4 & 150 & 48.5 & 89.53 & 85.5 & 28.3 & 78.83 \\
\hline 5 & 186 & 43.6 & 91.55 & 187 & 3.43 & 90.33 \\
\hline
\end{tabular}

\subsubsection{Potentiodynamic polarization studies}


The potentiodynamic polarization data of mild steel in $1 \mathrm{M} \mathrm{HCl}$ and $0.5 \mathrm{M} \mathrm{H}_{2} \mathrm{SO}_{4}$ with and without ICE are given in Table 3 and corresponding Tafel plots are depicted in Fig. 6 and linear polarization curves are pictured in Fig. 7.
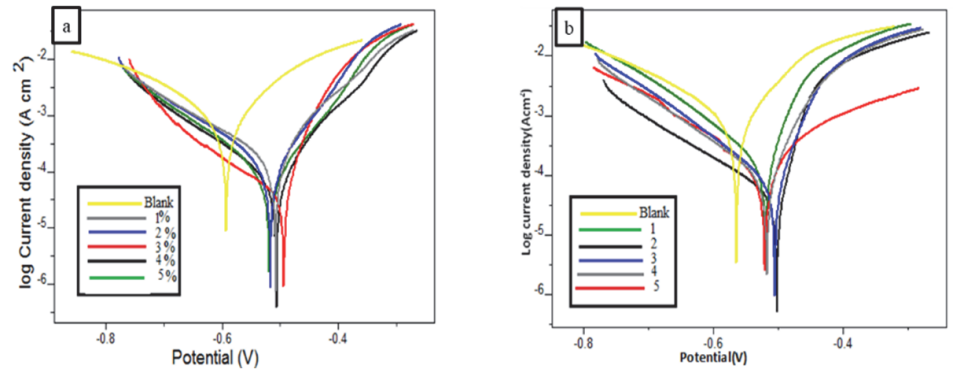

Fig. 6. a) Tafel plots of mild steel with and without ICE in a) $1 \mathrm{M} \mathrm{HCl}$ and b) $0.5 \mathrm{M} \mathrm{H}_{2} \mathrm{SO}_{4}$
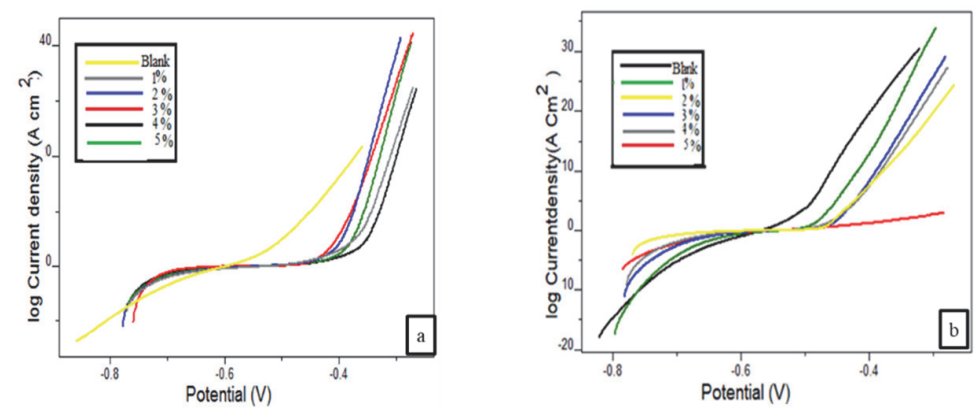

Fig. 7. Linear polarization curves of mild steel with and without ICE in a) $1 \mathrm{M} \mathrm{HCl}$ and b) $0.5 \mathrm{M}$ $\mathrm{H}_{2} \mathrm{SO}_{4}$

Table 3. Potentiodynamic polarization parameters for mild steel corrosion in $1 \mathrm{M} \mathrm{HCl}$ and $0.5 \mathrm{M}$ $\mathrm{H}_{2} \mathrm{SO}_{4}$ with various concentrations of ICE

\begin{tabular}{|c|c|c|c|c|c|c|}
\hline Acid & Conc. (v/v\%) & $E_{\text {corr }}(m V)$ & $\mathrm{I}_{\text {corr }}\left(\mu \mathrm{Acm}^{2}\right)$ & $\mathrm{b}_{\mathrm{a}}(\mathrm{mv} / \mathrm{dec})$ & $-\mathrm{b}_{\mathrm{c}}(\mathrm{mv} / \mathrm{dec})$ & $\% \eta_{\text {pol }}$ \\
\hline \multirow{6}{*}{$\begin{array}{l}1 \mathrm{M} \\
\mathrm{HCl}\end{array}$} & 0 & -597.9 & 1240 & 166 & 221 & -- \\
\hline & 1 & -522.8 & 193.6 & 106 & 170 & 84.41 \\
\hline & 2 & -504.8 & 122.3 & 69 & 158 & 90.11 \\
\hline & 3 & -571.6 & 107.9 & 100 & 130 & 91.29 \\
\hline & 4 & -515.0 & 87.22 & 93 & 149 & 92.96 \\
\hline & 5 & -500.7 & 78.50 & 69 & 146 & 93.67 \\
\hline \multirow{6}{*}{$\begin{array}{c}0.5 \mathrm{M} \\
\mathrm{H}_{2} \mathrm{SO}_{4}\end{array}$} & 0 & -602.2 & 1616 & 184 & 193 & -- \\
\hline & 1 & -601.8 & 811.6 & 170 & 136 & 49.77 \\
\hline & 2 & -649.6 & 415.5 & 199 & 156 & 74.28 \\
\hline & 3 & -588.9 & 368.4 & 142 & 128 & 77.20 \\
\hline & 4 & -587.4 & 306.9 & 138 & 137 & 81.00 \\
\hline & 5 & -555.7 & 209.6 & 221 & 142 & 87.02 \\
\hline
\end{tabular}

The potentiodynamic polarization data reveals that the greater the concentration of ICE, the smaller is the corrosion current density. The inhibition efficiency is also seen to increase. The inhibition efficiency of ICE for mild steel reached an upper limit of $93.67 \%$ in $1 \mathrm{M} \mathrm{HCl}$ solution and $87.02 \%$ in $0.5 \mathrm{M} \mathrm{H}_{2} \mathrm{SO}_{4}$ solution at higher concentration. From the Tafel plots in Fig. 6, it is seen that both cathodic and anodic curves are influenced by the addition of various concentrations of ICE which shows the mixed type inhibition character of ICE.

\subsubsection{Electrochemical Noise analysis}

Fig. 8 represents the current noise for mild steel with and without various concentrations of ICE (1, $3,5 \mathrm{v} / \mathrm{v} \%$ ) in $1 \mathrm{M} \mathrm{HCl}$ and $0.5 \mathrm{M} \mathrm{H}_{2} \mathrm{SO}_{4}$. It is seen that if the concentration of ICE is increased, the protecting power of ICE is also increased. For inhibitor molecules, current and potential noise is lower 
than the uninhibited system. Higher magnitude of potential noise signal of uninhibited acid media indicates appreciable localised metallic corrosion on metal surface ${ }^{23}$.
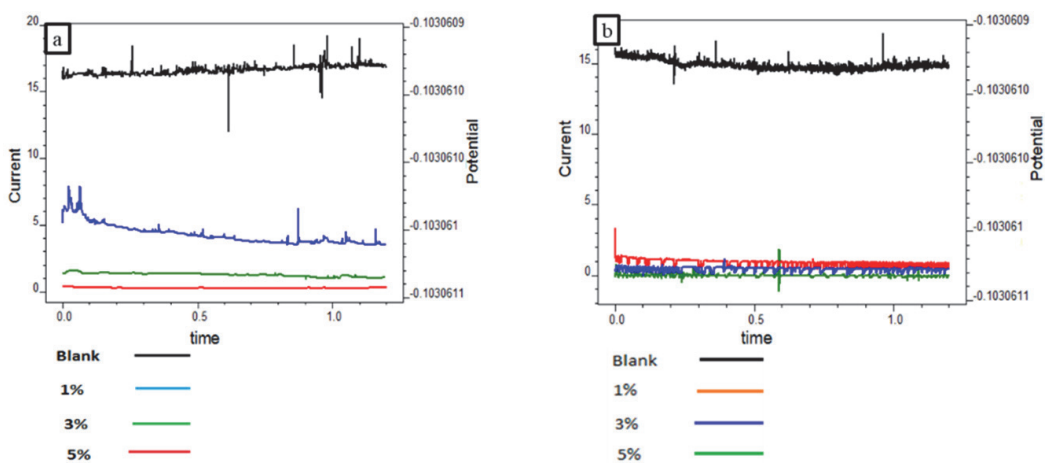

Fig. 8. Current noise for mild steel with and without ICE in a) $1 \mathrm{M} \mathrm{HCl} \mathrm{b)} 0.5 \mathrm{M} \mathrm{H}_{2} \mathrm{SO}_{4}$

The frequency-domain analysis of noise parameters results from the Power Spectral Density (PSD) of the corresponding system. PSD doesn't affect time and signal statistics ${ }^{24}$. The time-dependent noise parameters were converted into PSD plots by Fast Fourier Transformation (FFT) method in the Ivium software. Maximum entropy method (MEM) was introduced by Burge for better spectral resolution.

PSD plots in Fig. 9 reveal that the magnitude of the signals is higher for blank metal than metals with various concentrations of $\operatorname{ICE}(1,3,5 \mathrm{v} / \mathrm{v} \%)$ in $1 \mathrm{M} \mathrm{HCl}$ and $0.5 \mathrm{M} \mathrm{H}_{2} \mathrm{SO}_{4}$. This indicates a considerable amount of localised corrosion on the mild steel surface in the absence of ICE. As the concentration of ICE becomes greater, the magnitude of the noise signal decreases showing its anticorrosion property against mild steel in both acid solutions.
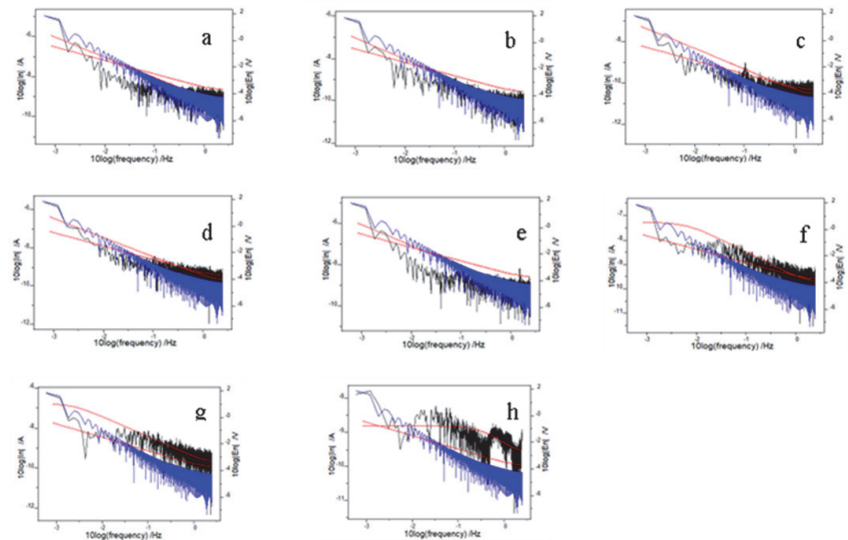

Fig. 9. Power spectral density of mild steel in $1 \mathrm{M} \mathrm{HCl}$ a) without ICE b) $1 \%$ ICE c) $3 \%$ ICE d) $5 \%$ ICE; Power spectral density of mild steel in $0.5 \mathrm{M} \mathrm{H}_{2} \mathrm{SO}_{4}$ e) without ICE f) $1 \%$ ICE g) $3 \%$ ICE h) $5 \%$ ICE

\subsection{Adsorption studies}

The mechanism of corrosion inhibition between inhibitor molecules and mild steel metal was illustrated using adsorption isotherms. Several adsorption isotherms like Langmuir, El-Awady, Frumkin, Temkin, Freundlich, and Flory-Huggins were considered for the study. The best suitable isotherm was detected using the value of correlation coefficient $\left(\mathrm{R}^{2}\right)$.

In this study, the metal-ICE interaction was observed to be obeying Langmuir adsorption isotherm. According to Langmuir adsorption isotherm, there are a large number of similar adsorption sites and little chance for lateral interaction. Equation (2) shown below explain Langmuir adsorption isotherm as $^{25}$ 
$\frac{C_{i n h}}{\theta}=\frac{1}{K_{a d s}}+C_{i n h}$

where $C_{i n h}, K_{a d s}$ and $\theta$ represent the concentration of inhibitor, equilibrium constant and the surface coverage respectively.

Standard free energy of adsorption $\Delta \mathrm{G}^{0}$ ads can be derived from the given value of $\mathrm{K}_{\text {ads }}$ using Eq. (3) ${ }^{26}$.

$$
\Delta \mathrm{G}^{0}{ }_{\mathrm{ads}}=-\mathrm{RT} \ln \left(55.5 \mathrm{~K}_{\mathrm{ads}}\right)
$$

where 55.5 is the molar concentration of water, $\mathrm{R}$ is the universal gas constant and $\mathrm{T}$ is the temperature in $\mathrm{K}$. The value of $\Delta \mathrm{G}^{0}$ ads determines whether the interaction between the inhibitor molecules and the metal surface is physisorption or chemisorption. If it is up to $-20 \mathrm{~kJ} / \mathrm{mol}$, the nature of the interaction is physisorption, whereas if it is more negative than $-40 \mathrm{~kJ} / \mathrm{mol}$, interaction is chemisorption.
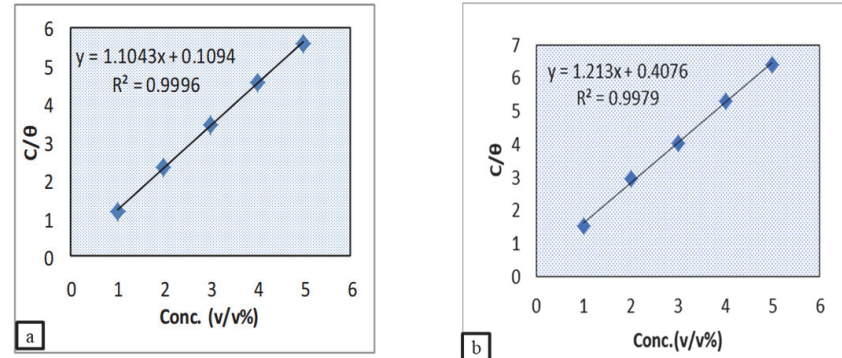

Fig. 10. Langmuir adsorption isotherm of ICE on mild steel in a) $1 \mathrm{M} \mathrm{HCl} \mathrm{b)} 0.5 \mathrm{M} \mathrm{H}_{2} \mathrm{SO}_{4}$ at $28^{0} \mathrm{c}$.

From the values of $\mathrm{R}^{2}$ in Fig. 10, it can be seen that Langmuir adsorption isotherm is the best suitable one for the adsorption of ICE on mild steel. The calculated $\Delta \mathrm{G}_{\text {ads }}^{0}$ for ICE are -32.88 and $-29.58 \mathrm{~kJ} / \mathrm{mol}$ in $1 \mathrm{M} \mathrm{HCl}$ and $0.5 \mathrm{M} \mathrm{H}_{2} \mathrm{SO}_{4}$ respectively shows that an electrostatic and chemical interaction exists between the inhibitor and the charged metal surface. ICE is composed of various organic compounds in it. The major component of Ixora coccinea leaves is ixorene. The adsorption of all the components of ICE on the mild steel surface may be attributed to the inhibitive action of the extract. Fig. 11 represents the predominant interaction of the major component ixorene with the mild steel surface. By transferring electrons from the Oxygen atom present in the -OH group and the interaction through the double bonds, ixorene molecules can be adsorbed onto the mild steel surface.

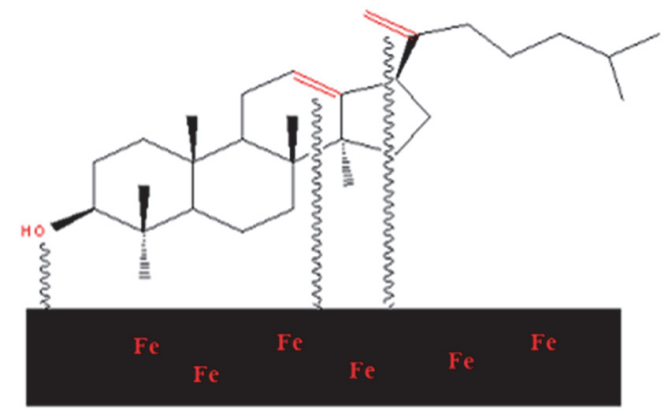

Fig. 11. Interaction diagram between Ixorene and mild steel surface

\subsection{Suface Morphological Studies}

To strengthen the understanding of the mechanism of ICE on the surface of mild steel, morphological studies were performed by taking the SEM images of metal coupons. Fig. 12a shows the SEM picture of smoothening mild steel metal. Figs. 12b, c, d, e shows the surface of mild steel metal after immersion in $1 \mathrm{M} \mathrm{HCl}$ and $0.5 \mathrm{M} \mathrm{H}_{2} \mathrm{SO}_{4}$ respectively without and with ICE. The SEM 
images clearly exhibit that the surface is severely damaged in the absence of the inhibitor ICE. It could be seen that the surface corrosion is getting reduced in $\mathrm{HCl}$ solution with ICE and the surface is more smooth and perfect in it than $\mathrm{H}_{2} \mathrm{SO}_{4}$ solution. So it can be confirmed that ICE acts as an excellent green corrosion inhibitor in acidic media.

\subsection{Quantum mechanical calculations}

Quantum mechanical parameters like $E_{\text {HOMO }}, E_{\text {LUMO }}, \Delta E$, Ionisation energy (I), Electron affinity (A), Chemical potential, electronegativity $(\chi)$, hardness $(\eta)$ and the number of transferred electrons $(\Delta N)$ of ixorene are tabulated in Table 4. The HOMO and LUMO pictures of ixorene are depicted in Fig. 13. The $\Delta E$ value is low for ixorene, which indicates that ICE has remarkable inhibition efficiency. This low $\Delta E$ value $4.884 \mathrm{eV}$ of ixorene attributes the low energy requirement for the transfer of electrons from HOMO of ixorene to the vacant orbitals of Fe. The $\Delta N$ values provide information regarding the interaction between donor-acceptor molecules ${ }^{27}$. This in turn proves agreement between quantum mechanical calculations and experimental results.

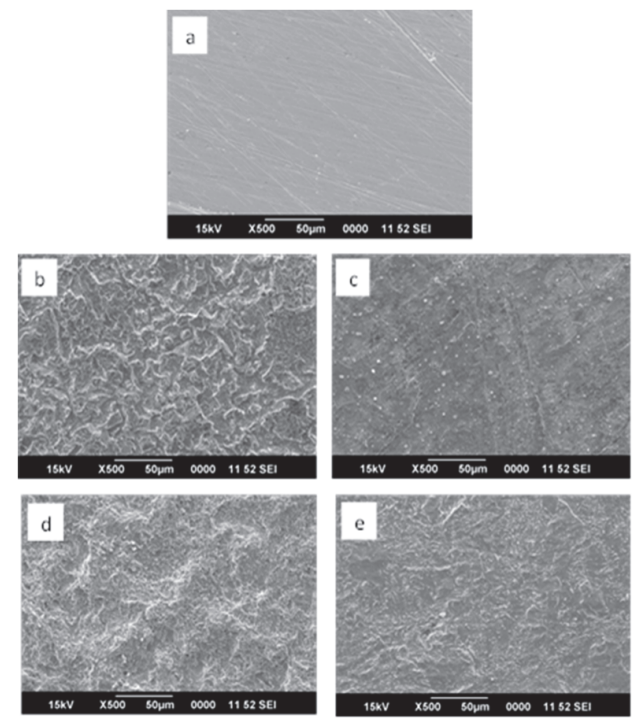

Fig. 12. SEM pictures of mild steel metal a) bare b) in $1 \mathrm{M} \mathrm{HCl} \mathrm{c)} \mathrm{in} 1 \mathrm{M} \mathrm{HCl}$ with ICE d) in $0.5 \mathrm{M}$ $\mathrm{H}_{2} \mathrm{SO}_{4}$ e) in $0.5 \mathrm{M} \mathrm{H}_{2} \mathrm{SO}_{4}$ with ICE.
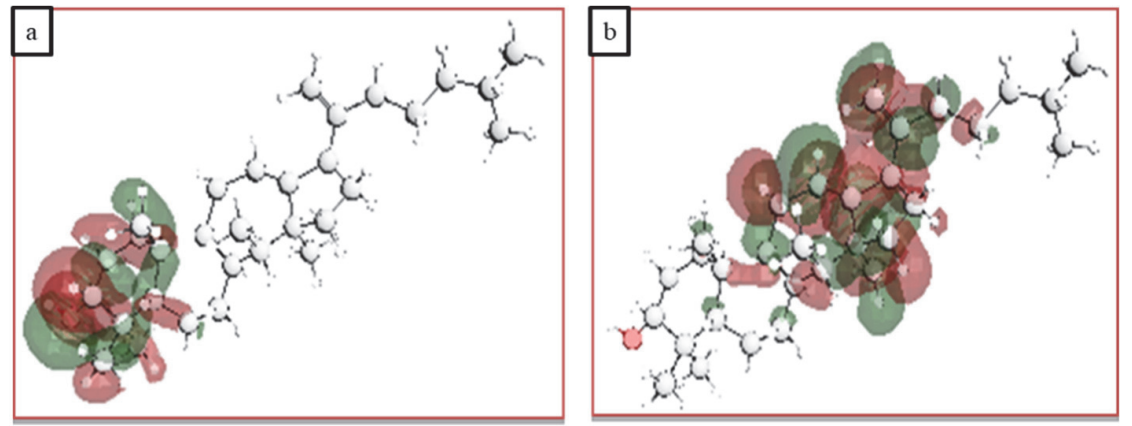

Fig. 13. A) HOMO and b) LUMO of Ixorene

Table 4. Quantum mechanical parameters of Ixorene

\begin{tabular}{lccccccccc}
\hline Molecule & $\begin{array}{c}\mathrm{E}_{\text {Hомо }} \\
(\mathrm{eV})\end{array}$ & $\begin{array}{c}\mathrm{E}_{\text {LUmo }} \\
(\mathrm{eV})\end{array}$ & $\begin{array}{c}\Delta \mathrm{E} \\
(\mathrm{eV})\end{array}$ & $\mathrm{I}$ & $\mathrm{A}$ & $\begin{array}{c}\text { Chemical } \\
\text { Potential }\end{array}$ & $\begin{array}{c}\text { Electronegativity } \\
(\mathrm{X})\end{array}$ & $\begin{array}{c}\text { Hardness } \\
(\eta)\end{array}$ & $\Delta \mathrm{N}$ \\
\hline Ixorene & -3.347 & 1.537 & 4.884 & 3.347 & -1.537 & -0.905 & 0.905 & 2.442 & 1.2479 \\
\hline
\end{tabular}




\section{Conclusions}

$>$ Ixora coccinea leaf extract (ICE) acts as an efficient green inhibitor for corrosion of mild steel in $\mathrm{HCl}$ and $\mathrm{H}_{2} \mathrm{SO}_{4}$ medium. As the concentration of the inhibitor increases, the protecting power also increases.

$>$ On comparing, ICE in $\mathrm{HCl}$ medium shows higher efficiency than $\mathrm{H}_{2} \mathrm{SO}_{4}$ medium.

$>$ UV-Visible spectrum of extract solutions suggests the possibility of adsorption of constituents present in ICE and also proves the inhibition capacity of ICE.

$>$ Electrochemical impedance analysis exhibits that charge transfer resistance increases and double layer capacitance decreases according to the concentration of ICE.

$>$ Potentiodynamic polarisation measurements exhibit a mixed type character of inhibition for ICE

$>$ Quantum mechanical calculations of ixorene - a major component present in ICE supports the inhibition power of ICE.

$>$ The adsorption studies of ICE shows that it obeys Langmiur adsorption isotherm.

$>$ The protecting power of ICE is also confirmed by surface morphological studies.

\section{Experimental}

\subsection{Inhibitor}

The Ixora coccinea leaves were washed with distilled water; shade dried for two weeks and made fine-grain using a grinder. $5 \mathrm{~g}$ of the granulated leaves was refluxed with $100 \mathrm{ml}$ ethanol for $4 \mathrm{hr}$. It is then filtered after keeping overnight and concentrated into $50 \mathrm{ml}$. The corrosion inhibition action of the Ixora coccinea extract (ICE) was analysed by preparing $1-5 \mathrm{v} / \mathrm{v} \%$ solutions in $1 \mathrm{M} \mathrm{HCl}$ and $0.5 \mathrm{M}$ $\mathrm{H}_{2} \mathrm{SO}_{4}$.

\subsection{Mild steel coupon preparation}

Mild steel composition \%:- C-12.37\% and Fe-87.63\% were the specimens used. For weight loss measurements, the metal specimens were cut into $1 \mathrm{~cm}^{2}$ coupon. For electrochemical analysis, the metal samples had a $1 \mathrm{~cm}^{2}$ surface area exposed to $100 \mathrm{ml}$ of the acidic medium. The metal coupons were physically abraded with 100, 220, 440, 800, 1000, 1500 and 2000 grade of sandpaper, washed with distilled water and acetone.

\subsection{Acid media preparation}

The electrolytic solution $1 \mathrm{M} \mathrm{HCl}$ and $0.5 \mathrm{M} \mathrm{H}_{2} \mathrm{SO}_{4}$ were made by dilution of analytical pure $\mathrm{HCl}$ and $\mathrm{H}_{2} \mathrm{SO}_{4}$ (Merck) using distilled water.

\section{$4.4 U V$-Visible Spectroscopy}

UV-Visible absorption spectrum of Ixora coccinea leaf extract (ICE) in $1 \mathrm{M} \mathrm{HCl}$ and $0.5 \mathrm{M} \mathrm{H}_{2} \mathrm{SO}_{4}$ separately was measured with UV- Visible spectrophotometer Shimadzu UV-1800, before and after $24 \mathrm{hrs}$ of immersion of mild steel.

\subsection{IR Spectroscopy}

IR spectrum of dried powdered samples of Ixora coccinea leaves was recorded in Shimadzu IR Affinity -1 model FT-IR spectrophotometer using KBr pellet method.

\subsection{Weight loss measurement}

It is a gravimetric method to measure the corrosion rate. The dimensions of the polished metal coupons were measured, which were then pre-weighed and immersed in $50 \mathrm{ml}$ acidic solutions of $1 \mathrm{M}$ 
$\mathrm{HCl}$ and $0.5 \mathrm{M} \mathrm{H}_{2} \mathrm{SO}_{4}$ separately, together with different inhibitor concentrations (1- $\left.5 \mathrm{v} / \mathrm{v} \%\right)$ for 24 hours at room temperature. After the immersion period, the metal coupons were washed with distilled water, dried and then weighed. The corrosion rate $(v)$ was calculated using equation $(4)^{28}$ :

$$
v=\frac{\mathrm{KW}}{\mathrm{DSt}^{\prime}}
$$

where $\mathrm{K}=87600$, W- average weight loss of coupon $(\mathrm{g})$, S- total area of the coupon $\left(\mathrm{cm}^{2}\right)$, D- density of metal $\left(\mathrm{g} \mathrm{cm}^{-3}\right)$, t- period of immersion (h). The percentage of inhibition efficiency was deduced from the values of $v$, using equation $(5)^{29}$.

$$
\eta \%=\frac{v_{0}-\mathrm{v}}{v_{0}} \times 100,
$$

where $v_{0}$ and $v$ indicate the rate of corrosion of metal coupons immersed in acid solutions in the absence and presence of the inhibitor ICE, respectively.

\subsection{Electrochemical Measurement}

Electrochemical investigations were done in a three-electrode cell using Ivium CompactStat electrochemical work station and IviumSoft software. A platinum electrode was employed as the counter electrode, and a saturated calomel electrode (SCE) was used as the reference electrode. Mild steel samples, $1 \mathrm{~cm}^{2}$ surface area exposed to $100 \mathrm{ml}$ acidic solutions, were made as a working electrode. The measurements were conducted at room temperature using $1 \mathrm{M} \mathrm{HCl}$ and $0.5 \mathrm{M} \mathrm{H}_{2} \mathrm{SO}_{4}$ with various concentrations ( $1-5 \mathrm{v} / \mathrm{v} \%$ ) of ICE. The EIS measurements were conducted across a frequency range of $1 \mathrm{KHz}$ to $100 \mathrm{mHz}$ using a signal amplitude of $10 \mathrm{mV}$. Using $\mathrm{R}_{\mathrm{ct}}$ values from Nyquist plots, corrosion inhibition efficiency of ICE was determined using equation $(6)^{30}$.

$$
\eta_{\mathrm{EIS}} \%=\frac{R^{\prime} c t-R_{c t}}{R^{\prime} c t} \times 100
$$

where $\mathrm{R}_{\text {ct }}$ and $\mathrm{R}_{\mathrm{ct}}$ are the charge transfer resistance of the working electrode in the presence and absence of inhibitor ICE, respectively. Potentiodynamic polarisation measurements were done under open circuit potential in the potential range of -250 to $+250 \mathrm{mV}$ at a scan rate of $1 \mathrm{mV} / \mathrm{sec}$. From the

polarisation curves, polarisation resistance values were obtained. From which percentage of inhibition efficiency, $\eta \%$ was found by Eq. $(7)^{31}$.

$\eta \%=\frac{R_{p}-R_{p}^{0}}{R_{p}} \times 100$

where $\mathrm{R}_{\mathrm{P}}{ }^{0}$ and $\mathrm{R}_{\mathrm{p}}$ are the polarization resistance values in the absence and presence of inhibitor ICE respectively.

Electrochemical noise (ECN) analysis was performed in a three-electrode system, which includes two mild steel electrodes having an exposed surface area of $1 \mathrm{~cm}^{2}$ and SCE as a reference electrode. Here one mild steel electrode acts as a working electrode and the other as a counter electrode. ECN analyses were performed for a period of $1200 \mathrm{~s}$.

\subsection{Scanning Electron Microscopy}

The surface morphological analysis of the inhibited and uninhibited mild steel surfaces in $1 \mathrm{M} \mathrm{HCl}$ and $0.5 \mathrm{M} \mathrm{H}_{2} \mathrm{SO}_{4}$ was performed by scanning electron microscope (JEOL Model JSM- 6390LV). The polished metal coupons of surface area $1 \mathrm{~cm}^{2}$ were dipped in acid solutions in the absence and presence of ICE. After keeping the systems for 24 hours at room temperature, they were removed and dried, which are then subjected to SEM analysis.

\subsection{Quantum mechanical calculations}

The corrosion inhibition power of inhibitors can be associated with the frontier molecular orbital energies $^{32}$. There is a donor-acceptor interaction between Fe vacant orbitals and the inhibitor filled 
molecular orbitals. This interaction can cause the prevention mechanism of metal corrosion ${ }^{33}$. As the $\Delta \mathrm{E}\left(E_{\mathrm{LUMO}}-E_{\mathrm{HOMO}}\right)$ value of inhibitors lowers, greater is the tendency to bind on the metal surface strongly ${ }^{34}$. Quantum mechanical calculations for the major component ixorene were carried out using DFT method by GAMMES software.

\section{References}

1. Mayakrishnan Prabakaran, Seung-Hyun Kim, Venkatesan Hemapriya, Mayakrishnan Gopiraman, Ick Sookim and Ill-Min chung. (2016) Rhus verniciflua as a green corrosion inhibitor for mild steel in $1 \mathrm{M}$ $\mathrm{H}_{2} \mathrm{SO}_{4}$. Rsc Adv., 6, 93259.

2. M. Jokar, T.Shahrabi Farahani and B.Ramezanzadeh, (2016) Electrochemical and surface characterizations of Morus alba pendula leaves extract(MAPLE) as a green corrosion inhibitor for steel in $1 \mathrm{M} \mathrm{HCl}, J$. Taiwan Inst. Chem. Eng. 63, 436-452

3. Patricia E Alvarez, M Victoria, Fiori-bimbi, Adriana Neskae, Silvia A Brandan, Claudio A Gervasi (2017) Rollinia Occidentalis extract as green corrosion inhibitor for carbon steel in $\mathrm{HCl}$ solution, J. Ind. Eng. Chem., 58, 92-99

4. I B Obot, N O Obi-Egbedi (2011) Anti-corrosive properties of Xanthone on mild steel corrosion in sulphuric acid: Experimental and theoretical investigations. Curr. Appl. Phys., 11, 382-392

5. K M Shainy, P Rugmini Ammal, K N Unni, Sailas Benjamin, Abraham Joseph. (2016) Surface interaction and corrosion inhibition of mild steel in hydrochloric acid using Pyoverdine, an eco-friendly biomolecule. J. Bio. Tribo. Corros., 2, 20

6. Akhil saxena, Dwarika Prasad, Rajesh Haldhar, Gurmeet singh, Akshay kumar, (2018) Use of Saraca ashoka extract as green corrosion inhibitor for mild steel in $0.5 \mathrm{M} \mathrm{H}_{2} \mathrm{SO}_{4}$, J.Mol., 258, 89-97

7. K K Anupama, K Ramya, K M Shainy, Abraham Joseph (2015) Adsorption and electrochemical studies of Pimenta dioica leaf extracts as corrosion inhibitor for mild steel in hydrochloric acid, Mater. Chem. Phys., 167, 28-41

8. P C Okafor, M E Ikpi, I E Uwah, E E Ebenso, U J Ekpe, S A Umoren (2008) Inhibitory action of Phyllanthus amarus extracts on the corrosion of mild steel in acidic media, Corros. Sci., 50, 2310-2317

9. Gopal Ji, Shadma Anjum, Shanthi Sundaran, Rajiv prakash, (2015) Musa Paradisica peel extract as green corrosion inhibitor for mild steel in $\mathrm{HCl}$ solution, Corros. Sci., 90, 107-117

10. Demian I Njoku, Ike Ukaga, Onyeachu B Ikenna, Emeka E Oguzie, Kanayo L Oguzie, Nkechi Ibisi, (2016) Natural products for materials protection: corrosion protection of aluminium in hydrochloric acid by Kola nitida extract, J. Mol., 219, 417-424

11. A Sexena, D Prasad, R Haldhar, (2017) Use of Butea monosperma extracts as green corrosion inhibitor for mild steel in $0.5 \mathrm{M} \mathrm{H}_{2} \mathrm{SO}_{4}$, Int. J. of Electrochem. Sci., 12, 8793-8805

12. Liu Li Liao, Shi M O, Hong Qun Luo, Nian Bing Li, (2017) Logan seed and peel as environmentally friendly corrosion inhibitor for mild steel in acid solutions: experimental and theoretical studies, JCOLI, 499, 110-119,

13. Mayakrishnan Prabakaran, Seung-Hyun Kim, Asokan Sasireka, Venkatesan Hemapriya, Ill-Min chung, (2016) $\beta$ - sitosterol isolated from rice hulls as an efficient corrosion inhibitor for mild steel in acidic environments, New J. Chem., 40, 1-846

14. Savita, Punita mourya, Namrata chaubey, Surendra kumar, V K Singh, M M Singh, (2016) Strychnos nuxvomica, Piper longum \& Mucuna pruriens seed extracts as eco-friendly corrosion inhibitors for copper in nitric acid, Rsc. Adv., 6, 95644-95655

15. M A Deyab, M M Osman, A E Elkholy, F El-Taib Heakal, (2017) Green approach towards corrosion inhibition of carbon steel in produced oil field water using lemon grass extract, Rsc. Adv., 7, 45241-45251

16. Ambreen Ikram, Muhammed Ali Versiani, Shumaila Shamshad, Salman Khalid Ahmed, Syed Tahir Ali, Shaheen Faizi, (2013) Ixorene, a new dammarane triterpene from the leaves of Ixora Coccinea Linn, Rec. Nat. Prod., 7 (4) 302-306

17. H Gao, Q. Li, Y. Dai, F. Luo, H.X.Zhang, (2010) High efficiency corrosion inhibitor 8-hydroxy quinolone and its synergistic effect with sodium dodecylbenzene sulphonate on AZ91D magnesium alloy, Corros. Sci., 52, 1603-1609 
18. Mohammad Mobin, Marziya Rizvi (2017) Polysaccharide from Plantago as a green corrosion inhibitor for carbon steel in 1M HCl solution Carbohydr. Polym. 160, 172-183.

19. N O Obi-Egbedi, I B Obot (2011) Inhibitive properties, thermodynamic and quantum chemical studies of alloxazine on mild steel corrosion in $\mathrm{H}_{2} \mathrm{SO}_{4}$, Corros. Sci., 53, 263-275.

20. Vinod P Raphael, K Joby Thomas, K S Shaju, Aby Paul (2014) Corrosion inhibition investigations of 3-acetylpyridine semicarbazone on carbon steel in hydrochloric acid medium, Res. Chem. Intermed., 40 (8), 2689-2701

21. K K Anupama, K M Shainy, Abraham Joseph (2016) Excellent anti-corrosion behaviour of Ruta Graveolens extract (RGE) for mild steel in hydrochloric acid: Electroanalytical studies on the effect of time, temperature and inhibitor concentration, J. Bio. Tribo. Corros., 2, 2

22. Fredy Kurniawan, Kartika A Madurani (2015) Electrochemical and optical microscopy study of red pepper seed oil corrosion inhibition by self-assembled monolayers (SAM) on 304 SS, Prog. Org. Coat., 88, 256-262

23. A. M V Homberg, E P M Van Westing, Tiedo Tinga, X Zhang, P J Oonincx, G M d Ferrari (2013) Novel time-frequency characterization of electrochemical noise data in corrosion studies using Hilbert spectra, Corros. Sci., 66, 97-110.

24. Janusz Smulko, Kazimierz Darowicki, Artur Zielinski (2002) Pitting corrosion in steel and electrochemical noise intensity, Electrochem. Commun., 4 (5), 388-391

25. Weiwei Zhang, Hui-Jing Li, Meirong Wang, Li-Juan Wang, Ai-Han Zhang, Yan-Chao Wu (2019) Highly effective inhibition of mild steel corrosion in $\mathrm{HCl}$ solution by using Pyrido[1,2-a]benzimidazoles, New J. Chem., 43, 413

26. K. S. Shaju, K. Joby Thomas, Vinod P Raphael, Aby Paul (2012) Synergistic effect of KI on corrosion inhibition of mild steel by polynuclear Schiff base in sulphuric acid, ISRN Corrosion, 2012, 8

27. Vinod P Raphael, Shaju K Shanmughan, Joby Thomas Kakkassery (2016) Monitoring the interaction of two heterocyclic compounds on carbon steel by electrochemical polarization, noise and quantum chemical studies, Int. J. Corros., 2016, 4204532

28. S Perumal, S Muthumanickam, A Elangovan, R Karthik, R Sayee Kannana, K K Mothilal (2017) Bauhinia tomentosa leaves extract as green corrosion inhibitor for mild steel in $1 \mathrm{M} \mathrm{HCl,} \mathrm{J.} \mathrm{Bio.} \mathrm{Tribo.}$ Corros., 3, 13.

29. Ragi Kooliyat, Joby Thomas Kakkassery, Vinod P Raphael, Sini Varghese Cheruvathur, Binsi M Paulson, (2019) Synthesis, cyclic voltammetric, electrochemical and gravimetric corrosion inhibition investigations of Schiff base derived from 5,5-Dimethyl-1,3-cyclohexanedione and 2-aminophenol on mild steel in $1 \mathrm{M} \mathrm{HCl}$ and $0.5 \mathrm{M} \mathrm{H}_{2} \mathrm{SO}_{4}$, Int. J. Electrochem., 2019, 1-13

30. Anupama K K, Ramya K, Abraham Joseph (2016) Electrochemical measurements \& theoretical calculations on the inhibitive interaction of Plectranthus ambionicus leaf extract with mild steel in hydrochloric acid, J. measurement, 95, 297-305

31. M. Faustin, A. Maciuk, P. Salvin, C. Roos, M. Lebrini (2015) Corrosion inhibition of C38 steel by alkaloids extract of Geissopermum laeve in $1 \mathrm{M}$ hydrochloric acid: electrochemical and phytochemical studies, Corros. Sci., 92, 287-300

32. K. K. Anupama, Abraham Joseph (2018) Experimental and theoretical studies on Cinnamomum verum leaf extract and one of its major components, eugenol as environmentally benign corrosion inhibitors for mild steel in acid media, J. Bio. Tribo. Corros., 4, 30

33. M A Chidiebere, C E Ogukwe, Kanayo L Oguzie, Chukwuemeka N Eneh, Emeka E Oguzie (2012) Corrosion inhibition and adsorption behaviour of Punica granatum extract on mild steel in acidic environments: Experimental and theoretical studies, Pubs.acs.org/IECR, 51, 668-677

34. Ambrish singh, Ashish kumar, Tanay pramanik (2013) A theoretical approach to the study of some plant extracts as green corrosion inhibitor for mild steel in $\mathrm{HCl}$ solution, Orient. J. Chem., 29, 277-283

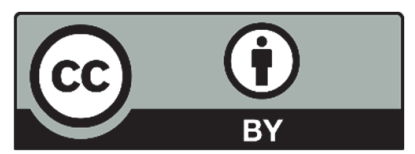

(C) 2021 by the authors; licensee Growing Science, Canada. This is an open access article distributed under the terms and conditions of the Creative Commons Attribution (CC-BY) license (http://creativecommons.org/licenses/by/4.0/). 